\title{
In Memoriam Professor Gordon Kimber 1932-2017
}

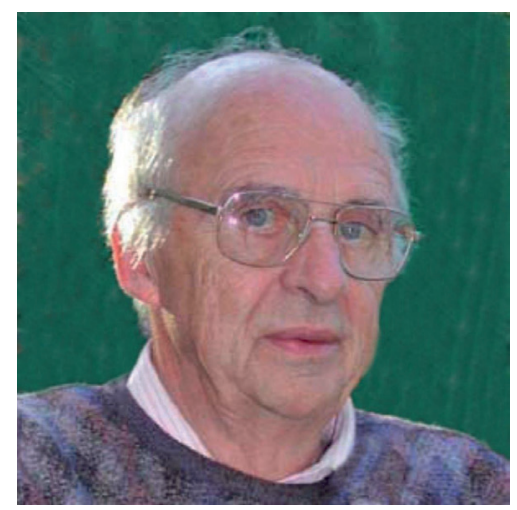

We are deeply saddened to announce that Prof. Gordon Kimber passed away 9th April 2017. He was a scientific acquaintance of the late Prof. Zoltán Barabás, who was the founder and the first Editor-in-Chief of Cereal Research Communications. Prof. Kimber was the member of the Editorial Board of the journal from the very start to the end of 2008 and the member of the Senior Editorial Board since 2009.

He was born 21st July 1932 in Manchester, England. He earned his B.Sc. in Botany at the University of London in 1954, his Ph.D. in Genetics at the University of Manchester in 1961 and his D.Sc. at the University of London in 1986.

He served as Scientific Officer and later as Senior Scientific Officer at the Plant Breeding Institute, Cambridge 1958-1967. He became Associate Professor (1967-1972), Professor (1972-1994) and Professor Emeritus (1994-2017) at the University of MissouriColumbia, USA.

Prof. Kimber had a distinguished career as scientist, professor and author of numerous scientific papers and book chapters. He was an endlessly curious person and the quote of Rudyard Kipling was his favorite, "My interest in natural things is among my earliest memories. Discovering that plants grew from seeds was perhaps the beginning of my curiosity".

As scientist, his main fields of interest were regulation of pairing in wheat, wheat haploids, wheat cytogenetics, the B genome in wheat, the course of evolution in wheat, Giemsa staining of wheat chromosomes, wheat-barley hybrid and amphiploid, use of wheat aneuploids, utilization of wide hybrids in wheat, genetic and genomic analysis in wheat, meiosis in wide hybrids. As invited lecturer he gave a great number of presentations about these scientific topics worldwide at research institutions and universities in the USA, UK, Australia, Europe, China, Israel and Japan. He visited Hungary as an invited lecturer twice. He came to Szeged, Hungary in 1976 and read the presentation "Developments in the evolution of wheat", and he was invited speaker at the Hungarian Academy of Sciences in 1991, where he presented "The choice of the best method for the 
introduction of alien variation in wheat. The meiotic analysis of genomic relationships in diploids."

He was the chairman, secretary, co-organizer, organizer or the member of the international organizing committees of eight international conferences in different parts of the world, most of them focusing on wheat genetics and chromosome engineering from 1973 to 1994. He was honoured with a Deed of Appreciation for his exceptional contribution to studying wheat, in Kyoto, Japan on the 6th International Wheat Genetics Symposium in 1983.

Not only was he an internationally appreciated lecturer but also did remarkable scientific research in foreign countries, including his activity as Kellogg Foundation Fellow (1963-1964), United Nations Scientific Expert in India (1970-1971), Japan Society for the Promotion of Science Fellow (1990), Scientific Advisor, Laboratory of Plant Cell and Chromosome Engineering, Bejing, China (1992-1995) and MASUA Honour Lecturer (1987-1988). He was an enthusiastic international scientific cooperator.

As Professor of the University of Missouri-Columbia he taught the following subjects: Cytegenetics, Cytogenetics Laboratory, Genetic Engineering (with Professor Redei), Basic Plant Genetics and Plant Genetics Problems. He was the leader of the thesis of numerous graduate students and enhanced their receiving the Ph.D. degree. He also served as the member of graduate committees.

He was also engaged in forming the university policy and campus life being the member or chair of a broad spectrum of councils and committees of the university (19701992).

He was the member of scientific associations as well, namely, of the Genetics Societies of Great Britain, America and Canada. He was the Chapter President of the American Association of University Professors 1984-1988.

He was also active in editing scientific publications. He was the Consulting Editor of Butterworths Press and Member of the Editorial Board of Cereal Research Communications.

His multifaceted activities were recognized with the awards Gamma Sigma Delta, Research Award of Merit and Sigma Xi, Faculty Research Award, both of them in 1988.

He was an unbelievably creative, bright and tireless personality with lots of energy, wide interest and full of new ideas. Photography was an ongoing private passion throughout his life and he was often behind the camera.

We share the deep sorrow for him with his family and wife, who, despite of her bereavement, supported us affectionately in writing this memorial. In Prof. Kimber's person we have lost a great and at the same time humble scientist, who was eager to share the scientific information with students, graduates, colleagues and other scientists. We shall keep his memory in our hearts and minds. May he rest in peace.

$\begin{array}{cc}\text { János Pauk } & \text { Elizabeth Buza } \\ \text { Editor-in-Chief } & \text { Technical Editor }\end{array}$

